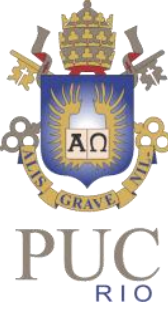

PONTIFÍCIA UNIVERSIDADE CATÓLICA DO RIO DE JANEIRO

Efeitos da inclusão de PCDs na cultura organizacional da Reserva

Eduardo Drummond Leonardos

Trabalho de conclusão de curso

Departamento de Administração

Graduação em Administração de empresa

Rio de Janeiro, Dezembro de 2019 


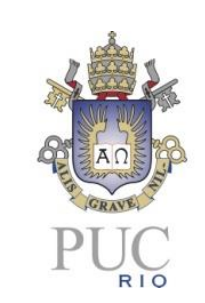

Eduardo Drummond Leonardos

\title{
Efeitos da inclusão de PCDs na cultura organizacional da Reserva
}

\section{Trabalho de conclusão de curso}

\begin{abstract}
Trabalho de Conclusão de Curso, apresentado ao programa de graduação em Administração da PUC-Rio como requisito parcial para a obtenção do titulo de graduação em Administração.
\end{abstract}

Orientador: Marco Aurélio de Sá Ribeiro 


\section{Agradecimentos:}

Agradeço a minha família por todo suporte financeiro e emocional que me ajudaram a concluir o curso de Administração de empresas numa universidade como a PUC.

Também agradeço aos professores que estiveram comigo nessa grande jornada, do primeiro ao ultimo período, contribuindo muito para meu desenvolvimento pessoal e profissional.

Agradecimento especial ao meu orientador Marco Aurélio de Sá Ribeiro que esteve sempre presente e me ajudou muito na construção desse trabalho. 


\section{Resumo:}

Leonardos, Eduardo Drummond. Estudo sobre os efeitos da inclusão de PCDs na cultura organizacional da empresa Reserva, Rio de Janeiro, 2019, ? p. Trabalho de conclusão de curso- Departamento de Administração. Pontifícia Universidade Católica do Rio de Janeiro.

O trabalho foi feito com a intenção de analisar os efeitos da inclusão de PCDs na cultura organizacional da Reserva. Foi estudado sua cultura organizacional em relação a inclusão de PCDs, analisando todas suas características. Observando como que está sendo feito o gerenciamento cultural da empresa e analisando as políticas de $\mathrm{RH}$ para essa mudança de pensamentos sobre a inclusão de PCDs dentro da empresa, para enfim chegarmos na análise da mudança cultural da Reserva.

Palavras chaves: Cultura Organizacional, mudança organizacional, pessoas com deficiência e $\mathrm{RH}$. 


\begin{abstract}
:
Drummond, Eduardo. Study on the effects of including PCDs on the organizational culture of Reserva, Rio de Janeiro, 2019,? P. Course conclusion work- Department of Administration. Pontifical Catholic University of Rio de Janeiro.

The work was done with the intention of analyzing the effects of the inclusion of PCDs in the organizational culture of the Reserve. The organizational culture of the Reserve was studied in relation to the inclusion of PCDs, analyzing the characteristics of the organizational culture of the Reserve. Noting how the company's cultural management is being done and analyzing HR policies for this change of thinking about the inclusion of PCDs within the company, so that we can finally look at the Reserve's cultural change analysis.
\end{abstract}

Keys words: Organizational Culture, organizational change, people with disabilities and HR. 


\section{Sumario:}

10 tema e o problema de estudo 8

1.1 Introdução ao tema e ao problema do estudo 8

1.2. Objetivo do estudo 9

1.3. Objetivos intermediários do estudo 9

1.4. Delimitação e foco do estudo 10

1.5. Relevância do estudo 10

2 Referencial Teórico 11

2.1.Cultura Organizacional 11

2.1.1 Cultura Organizacional Adaptativa 13

2.2 Características da Cultura Organizacional 14

2.3. Mudança Organizacional 14

2.4.Papel do Líder no Gerenciamento Cultural 16

2.5 Políticas de $\mathrm{RH} 17$

3 Metodologia 18

3.1. Tipo de Pesquisa 18

3.2. Universo e amostra da pesquisa 18

3.3 Coleta de dados 18

3.4 Tratamento dos dados 19

3.5 Limitações do método 19

4 Análise da Pesquisa 20

4.1 O cenário atual da Reserva 20

4.2 Processo de inclusão e trabalho em equipe 21

4.3 Efeitos da Inclusão 22

4.4 Por que mudar? 23

4.5 Etapas da mudança 24 
4.6 Cultura Organizacional 25

5 Conclusão 27

6. Referências bibliográficas 29

Obs: $\mathrm{PcD}=$ pessoa com deficiencia 
1 O tema e o problema de estudo:

1.1 Introdução ao tema e ao problema do estudo

Apenas em 1970, os direitos das pessoas com deficiência tiveram espaço na agenda internacional da política internacional(BAHIA e Schommer 2010), sendo que em 1975 a ONU aprovou a Declaração dos Direitos das Pessoas Portadoras de Deficiência(Lopes, 2005), e essa aprovação foi 0 começo do processo de assegurar que os PCDs tivessem oportunidade de participar da vida comunitária em igualdade de condições com os demais membros da comunidade.

Em 1983, a Organização Internacional do Trabalho(OIT) falou da necessidade da adoção de medidas que fossem capazes de incrementar e favorecer o acesso dos portadores de deficiência a ter uma profissão (RIBEIRO e CARNEIRO, 2009), porém no Brasil, apenas em 1989 deu-se inicio a inclusão do deficiente com a implementação da lei 7853 (Política Nacional para a Integração da Pessoa Portadora de Deficiência) e instituiu a política de cotas empregatícias para portadores de deficiência por meio da Lei 8.112, de 1990 (para o setor público), e da Lei 8.213, de 1991 (conhecida como Lei de Cotas, para empresas privadas), regulamentada apenas em 1999, por meio do Decreto 3.298.

A partir dessa lei, que determinava que as empresas com mais de 100 funcionários reservem de $2 \%$ a $5 \%$ das vagas para PcDs (lei 8.213 de 1991, no artigo 93), houve um crescimento de pessoas com necessidades especiais nas empresas. Porém, apesar do crescimento, podemos notar um pré-conceito tanto da sociedade quanto das empresas, que em muitas situações não enxergam essas pessoas como profissionais qualificados.

No início desse século no Brasil, diversas pessoas com algum tipo de deficiência estavam sendo discriminadas pela sociedade, sendo excluídas do mercado de trabalho, sofrendo um processo de exclusão social, pois a nossa sociedade em alguns momentos acaba inabilitando os Pcds, já os julgando por conta de sua limitação, o que mostra uma separação em nossa sociedade por conta dessa diversidade.

A Reserva passa pelo processo de incluir funcionários PcDs em sua empresa para enaltecer a inclusão social, valorizando a qualidade de cada pessoa por achar que cada um pode contribuir de alguma maneira para a sociedade, acreditando que para inclusão desses colaboradores deve ser feito um trabalho com bastante atenção, pois quando incluímos uma pessoa em nosso "mundo", devemos abrir as portas para conhecer toda complexidade da questão e assim buscar a melhor forma de abraça-las. 
Segundo estudo divulgado durante o CCLAC 2019, evento de capitalismo consciente em São Paulo. A Reserva esta entre as 22 empresas mais humanizadas do Brasil, esse estudo foi baseado em três critérios, sendo eles a geração de valor financeiro, sustentabilidade e bem-estar social. A empresa humanizada é aquela que é capaz de envolver e mobilizar pessoas (de dentro e de fora do seu âmbito) em prol da construção de um futuro melhor para elas e para a sociedade.

A deficiência em muitas situações é vista como uma doença ou um empecilho para realizar seus objetivos, mas na verdade a deficiência nada mais é do que mais um tipo de diversidade para a empresa. A Reserva acredita que a diversidade é fundamental para 0 andamento de seus negócios, pois com o apoio de diversos colaboradores de diferentes gêneros, idades, culturas, classes sociais, orientações sexuais, condições físicas e intelectuais e até padrões estéticos, a empresa ampliará a visão de seus negócios.

Assim, a inclusão social torna-se o grande desafio para a empresa, pois o processo de inclusão dessas pessoas não foi feito da melhor forma pela empresa em anos anteriores, visto que a Reserva não tratava esse assunto com a importância que deveria.

A Reserva acredita que essa diversidade pode afetar a cultura da empresa, visto que a partir da cooperação e da tolerância, a empresa passe a ter uma maior experiência, incentivando o coletivo, gerando pensamentos mais críticos e criativos.

Desta forma, a pergunta que vai nortear esse estudo é:

Qual é o impacto dessa diversidade na Cultura organizacional da empresa Reserva?

\subsection{Objetivo do estudo:}

O objetivo desse estudo é analisar os efeitos do processo de inclusão de PcDs na cultura organizacional de uma das maiores e mais conhecidas empresas de moda do Brasil, verificando como que a inserção dessas pessoas afeta a identidade da Reserva.

1.3Objetivos intermediários do estudo:

Para o alcance do objetivo final do estudo, estão previstos como objetivo intermediários a serem alcançados:

$\checkmark$ Avaliar os desafios iniciais vivenciados por esse grupo

$\checkmark$ Apresentar as barreiras enfrentadas pelos PcDs, após entrar no mercado de trabalho

$\checkmark$ Medir os efeitos da inclusão para a cultura da empresa 


\subsection{Delimitação e foco do estudo}

O estudo terá foco na empresa de roupas Reserva e não irá avaliar o efeito da diversidade em outras empresas no Brasil ou no mundo. O estudo será delimitado a observar os efeitos gerados a partir dessa inclusão, observando os efeitos que essa entrada vai gerar na cultura organizacional da empresa Reserva que está no processo de aumentar o número de funcionários PcDs em seu escritório localizado no Rio de Janeiro para aumentar a diversidade dentro da empresa.

Com isso, iremos avaliar como que a entrada dessas pessoas pode afetar a cultura organizacional da empresa.

\subsection{Relevância do Estudo}

Esse estudo tem grande relevância para a Reserva e também para muitas empresas no mundo, já que por meio dele, a Reserva e outras empresas conhecerão a importância dessa diversidade para a cultura organizacional da empresa, mostrando que com o apoio de diferentes colaboradores a empresa conseguirá ter uma melhor visão de seus negócios, pois a pluralidade irá permitir que um mesmo assunto seja tratado com diversas perspectivas criando um ambiente propício para inovação, realçando que o preconceito contra os PcDs prejudica a própria empresa. 


\section{Referencial Teórico}

O tema cultura organizacional foi citado com o propósito de desenvolver a ideia sobre a importância desse aspecto ao falamos sobre mudanças organizacionais. O paralelo entre cultura e cultura organizacional é fundamental para isso, sendo fundamental reconhecer a definição sobre cultura organizacional adaptativa que será um temo de extrema importância para esse estudo.

A cultura é o conjunto de tradições, crenças e valores de determinado grupo social, ela representa o patrimônio social de uma sociedade e a soma de padrões do comportamento humano, sendo responsável pela formação de uma sociedade mais justa para todos.

Sobre o tema mudança organizacional, seguiremos o pensamento do pai da inclusão social no Brasil Romeu Kasumi Sassaki, no qual a sociedade deve se adaptar para inclusão de pessoas com necessidades especiais, visto que essas pessoas buscam encontrar scu papel na sociedade. O homem acaba sendo, personagem chave nesse processo, tendo as ações do ser humano um papel de extrema importância na formação da cultura da empresa, visto que cada pessoa têm suas próprias características e individualidades que podem afetar a entrada dessas pessoas na organização. A percepção de que existem fatores que criam significados e possibilidade de existência em um grupo em determinado ambiente são elementos fundamentais para a compreensão dos efeitos do processo de inclusão social.

O estudo do gerenciamento cultural irá mostrar agentes facilitadores do processo de inclusão. A inserção de PcDs no mercado de trabalho geram mudanças na estrutura da empresa, como por exemplo, adequações de acessibilidade que irão proporcionar condições mais adequadas na hora de receber essas pessoas.

Com a chegada dessa pessoa a equipe e a rotina de trabalho, a empresa começa a desenvolver uma cultura de inclusão, onde a igualdade e o respeito são fundamentais para a empresa buscar ser mais inclusiva.

\subsection{Cultura Organizacional:}

Segundo: Sobral e Peci (2014):

"Sistema de valores e significados compartilhados pelos membros da organização, transmitidos por meio de historias, símbolos, linguagem, entre outros, que diferenciam uma organização da outra" 
O autor afirma que a cultura organizacional se refere à rede de concepções, normas e valores relacionados a todos os aspectos da vida organizacional, sendo a cultura, ainda que uma dimensão organizacional complexa e de difícil identificação, um mecanismo para a empresa se adaptar as mudanças constantes do ambiente externo e à integração eficaz dos processos internos, reduzindo o medo diante das surpresas geradas pelo ambiente.

A cultura organizacional, diferentemente de outras características, é uma característica intangível da empresa, embora gere manifestações concretas dentro da empresa, não é definida pelo nível hierárquico mais alto da organização, sendo importante na reprodução ou mudança cultural, diferentemente da cultura da sociedade onde a empresa atua, esta nela os valores e atitudes esperados, sem gerar diferencial claro no produto ou serviço comercializado, mas estando no centro e explanando vários sucessos empresariais.

O indivíduo busca entender o mundo de acordo com a diferença entre as pessoas, sendo que os PcDs têm papeis secundários na sociedade por conta do preconceito, tendo que driblar a ignorância para mostrar seu valor e engrenar na sua carreira profissional.

Para uma sociedade inclusiva, ela deve segurar os direitos de qualquer cidadão respeitando suas diferenças, particularidades e limitações, tendo a cultura um papel de extrema importância para formação do cidadão. Os valores culturais são um dos principais elementos da cultura, sendo um mecanismo que irá expor as mudanças trazidas de uma geração para outra.

Segundo Trice \& Beyer(1991), a cultura organizacional tem 6 principais características que são o caráter coletivo, uma cultura é o conjunto do que determinado grupo concorda em relação a percepção do mundo. Como a cultura simplifica o gerenciamento da ansiedade de seus colaboradores diante da incerteza, sendo essa a segunda característica. A terceira característica vem da sua historia: toda cultura tem traços do passado, onde as pessoas estão convivendo e aprendendo a confrontar os problemas enfrentados pelo grupo. A quarta característica é a natureza simbólica da cultura, com o simbolismo representando um personagem fundamental no dialogo e na demonstração cultural.

Embora, uma cultura crie a ideia de continuidade e prossiga ao passar do tempo, ela muda o tempo todo, sendo esse dinamismo a quinta característica e ela não é nítida e, embora ela passe por toda a organização e ande na vida de todos os funcionários, ela é de difícil compreensão.

Assim, o estudo da cultura organizacional é fundamental para entender diferentes interpretações do cotidiano da empresa. O diagnostico cultural 
direciona um olhar mais amplo para a empresa, permitindo analisar os limites e desejos da mesma, seguindo a restrição e imposição do ambiente.

Para a continuação desse estudo será utilizado à abordagem da cultura organizacional adaptativa que busca uma adaptação saudável ao ambiente externo, estando sempre prontos para as mudanças que forem necessárias.

\subsubsection{Cultura Organizacional Adaptativa:}

Segundo pesquisa da universidade de Harvard:

"Cultura caracterizada pela maior maleabilidade e flexibilidade frente as mudanças organizacionais, distinguindo-se pela capacidade de inovação e criatividade".(Sobral e Peci, 2014)

A cultura não é um obstáculo para empresa, mas sim um estimulador de mudanças de acordo com às necessidades organizacionais e as circunstâncias na qual a empresa atua frente as mutações do ambiente. Ela determina aquilo que é plausível, mostrando o que deve ser feito no centro da empresa, mas não necessariamente o que se deve fazer, visto que a cultura é um padrão funcional da organização, estando sujeita ao risco de perder seu valor ao longo do tempo.

Segundo Schein(2006), a cultura chega a partir do entendimento do grupo, a forma adequada de perceber, pensar e sentir os problemas. Ela é o modelo de crenças e pressupostos básicos compartilhados por uma equipe e construídos a partir do feedback relacionados a problemas de adaptação externa e integração interna.

Seguindo a visão do autor, a cultura pode ser analisada a partir de 3 níveis de manifestações culturais que são os artefatos que tocam as estruturas e processos organizacionais visíveis no encontro com um novo grupo com uma cultura nova, mas sendo perigoso pensarmos na cultura da empresa, apenas com esse nível.

Os valores e crenças encontrados na empresa são o segundo nível. É o que é transmitido e acertado pela equipe, condicionando o comportamento para o processo de socialização. É notável perceber que esses valores por ser um consenso do grupo nem sempre irão representar efetivamente cada membro do grupo.

O terceiro nível é composto pelos pressupostos básicos, sendo este o mais difícil de ser explicado, pois esta relacionado ao comportamento e posturas inconscientes vistas como claras, mas que devido a natureza humana podem ser adotadas de maneira automática, sendo esses elementos "invisíveis". 
Figura 1 - Níveis de cultura (Schein, 2009).

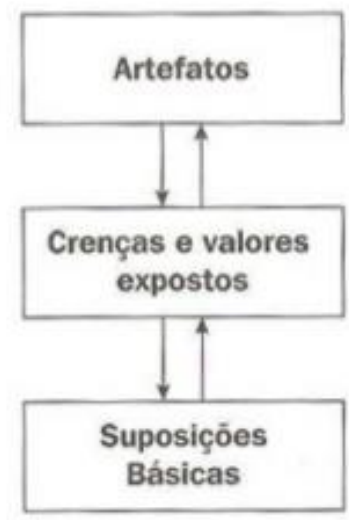

Estruturas e processos organizacionais visiveis (dificeis de decifrar)

Estratégias, metas, filosofias (justificativas expostas)

\subsection{Características da Cultura Organizacional:}

A Cultura organizacional é a identidade da empresa. Ela é caracterizada a partir dos elementos que a representam ou dos efeitos fornecidos em termos de comportamento.

A aclaração de certa cultura é um processo de difícil analise, onde o investigador tem que estar atento para seu próprio sistema de valores e como isso pode influencia-lo na sua análise, visto que a cultura é um termo que pode sofrer mudanças constantes de acordo com os valores e pressupostos de cada um.

A partir de tudo que foi dito, as organizações devem estar preparadas para a adaptação necessária imposta pelo ambiente, havendo respeito e tolerância para a entrada de novos funcionários.

\section{3:Mudança Organizacional}

Com a chegada de PCDS, as empresas terão que desenvolver um projeto para receber tais pessoas como seus funcionários. A realização de mudanças é um dos fatores mais importantes para atingir aquilo que é necessário.

Segundo Robbins (1999), as mudanças organizacionais "são atividades intencionais, pró-ativas e direcionadas para a obtenção das metas organizacionais". Ele aponta 6 características essenciais para a mudança: a natureza da força do trabalho, a tecnologia, os choques econômicos, a concorrência, as tendências sociais e a política mundial. Esses fatores estão presentes no dia a dia da empresa, fazendo repetidas pressões sobre a empresa.

Segundo Boyett (1999), a resistência as mudanças vem da percepção dos resultados negativos, onde as pessoas afetadas pela mudança passam a 
imaginar que o efeito será sempre negativo, do receio de mais trabalho com as pessoas imaginando que as mudanças aumentaram a carga de trabalho, necessidade de mudança de hábitos, onde a exigência dessas mudanças já estão internalizados, imperfeição na comunicação, onde os funcionários não são devidamente comunicados sobre os motivos da mudança, incapacidade de alinhar a organização como um todo, havendo problemas na coordenação que envolve a mudança e revolta por parte dos funcionários que é a defesa criada pelos membros da empresa contra a mudança.

Por outro lado, o autor mostra que a criação da necessidade passa por promover mudanças e que seus funcionários devem compreender essas mudanças para haver uma visão positiva sobre isso, a comunicação deve ser eficaz e efetiva para a transmissão e entendimento da mensagem, deve haver um desenvolvimento do grupo para promover a mudança, a organização deve enfrentar questões como a cultura organizacional, onde as mudanças reais e permanentes envolvem os fundamentos da organização e promover a participação de cada membro da empresa para a conscientização de cada funcionário ajudar nesse processo.

O processo de inclusão social tem papel de extrema importância nesse processo de mudança. A organização deve gerar condições de receber qualquer tipo de pessoa como seu funcionário. A cultura inclusiva busca dar maior atenção para seus funcionários. Ela reduz os conflitos dentro da empresa, havendo políticas bem estabelecidas com uma comunicação bem clara, reduzindo assim a chance de mal entendidos causados pela diversidade, havendo assim um cenário mais saudável dentro da empresa.

As organizações estão em fase de desconstrução e aprendizado sobre as mudanças que vem ocorrendo na sociedade, a inclusão social de PCDs no mercado de trabalho tem o papel de criar uma cultura empresarial que respeite as características individuais de cada um.

A empresa deve valorizar seus funcionários, visto que seus colaboradores são seres humanos cheios de sentimentos, problemas e questionamentos. Eles devem ser valorizados quando merecidos e questionados quando fizerem besteira e com o PCD não deve ser diferente.

A organização deve perceber que existem várias atitudes que podem ser incorporadas à produção de conteúdo que são orientadas para uma comunicação mais relevante e personalizada, sendo capaz de se conectar com as pessoas.

As transformações que ocorrem diariamente nos ambientes da empresa e os efeitos dessas mudanças sobre a cultura organizacional está interligada aos avanços da sociedade que busca desconstruir estereótipos que reproduzam padrões e comportamentos que não representam as pessoas e, 
consequentemente, não engajam e nem geram nenhuma conexão com a sociedade.

A criatividade tem papel fundamental para a empresa, sendo 0 trabalhador incentivado a buscar a inovação e assim ajudar na formação desses processos, onde qualquer funcionário se sinta seguro para trabalhar com segurança e confiança, respeitando sempre a diversidade dentro da empresa.

\subsection{Papel do líder no Gerenciamento cultural:}

Como gerenciar a cultura de uma organização? Pettigrew (2007) entende que para qualquer mudança na cultura da empresa terá que haver um processo humano complexo em que cada membro da empresa desempenha sua parte, como a percepção diferenciada, as buscas por eficiência e poder, as habilidades de liderança visionária, a duração das mudanças e os processos que mostram o momento ideal para a mudança.

Segundo Schein, a cultura organizacional começa com os lideres impondo seus valores e pressupostos sobre o mundo para sua equipe. Com o passar do tempo, esses pressupostos passam a ser a base sobre a qual o grupo constrói sua expressão da realidade e esta cultura criada passa a definir, inclusive, que tipos de líderes e de liderança serão aceitos no futuro pela organização.

A cultura emerge basicamente de três fontes: (1) As crenças, valores, e pressupostos dos fundadores da organização, (2) As experiências dos membros do grupo à medida que a organização evolui e (3) Novas crenças, valores e pressupostos trazidos para a organização por novos membros e líderes.

A inserção de PcDs no mercado de trabalho representa uma mudança dentro da empresa. A organização deve estar preparada para receber esse grupo da melhor forma, com isso o gerenciamento cultural terá um papel fundamental nesse procedimento, onde a empresa deve se adequar de todas as formas para estimular a inclusão dessas pessoas.

$\mathrm{Na}$ linha que considera a cultura gerenciável, existem duas linhas de pensamento que são o pragmatismo cultural que tem a visão da cultura como uma variável organizacional sendo manipulada para acolher as necessidades da empresa e o purismos cultural que não separa organização e cultura, tendo a visão de que a organização é uma cultura e essa cultura esta no coração da empresa(Hilal,1996).

Os dois tipos de abordagem do gerenciamento da cultura organizacional são a conformidade que é a preservação da ordem e continuidade e transformação que é a alteração dos padrões existentes (Bate, 1997). 
Prontamente a escolha de uma das duas e a eficiência que ela terá são pendentes de outros fatores do ambiente interno e do ambiente externo da empresa.

Para o gerenciamento da cultura da organização é necessário primeiro haver a compreensão dessa cultura, caracterizando com a maior clareza possível os atributos da cultura que se busca manter e os fatores que se pretendi alcançar. Segundo Schein (2004), o ciclo de vida das empresas determina que existem momentos mais vantajosos para o gerenciamento da cultura organizacional. Para a mudança da cultura a partir da inserção de PCDs, o gerenciamento cultural necessita de uma política de $\mathrm{RH}$ que favoreça a inclusão para que esse processo seja bem feito.

\subsection{Políticas de $\mathrm{RH}$ :}

Segundo Chiavenato, a administração de recursos humanos consiste em planejar, organizar, desenvolver, coordenar e controlar. O papel do Rh é atuar como um conciliador entre funcionário e organização, sendo sua avaliação fundamental para os recrutadores e gestores levem em consideração a habilidade, sem considerar a limitação dessas pessoas como um empecilho.

A política de recursos humanos deve avaliar a conciliação entre os processos explícitos e implícitos, analisando as consistências e inconsistências entre os dois. A empresa deve garantir acessibilidade para qualquer funcionário para que haja as mudanças que forem necessárias para receber essas pessoas, incluindo os gestores da empresa para mostrar a contribuição que essas pessoas podem gerar para empresa.

O treinamento desses profissionais deve gerar condições de desenvolver pessoalmente e profissionalmente qualquer funcionário sem haver diferença em relação ao objetivo do treinamento.

O acompanhamento é fundamental para garantir a ambientação do novo colaborador com a empresa e sua equipe. A analise do impacto dessa inclusão. para a cultura da empresa é a chave desse estudo, onde a analise da empresa Reserva relacionado ao que foi dito nesse capitulo vai ser fundamental para conclusão do trabalho. 


\section{Metodologia de pesquisa:}

\subsection{Método de pesquisa:}

Essa pesquisa usa o método qualitativo para enfatizar o caráter subjetivo da situação estudada. As técnicas e métodos estatísticos são dispensados nesse modelo, visto que o investigador se foca em características mais complexas e não-quantificáveis, como o comportamento, as expressões, os sentimentos, etc. No que diz respeito aos resultados da investigação, ele irá proporcionar diversas interpretações sobre o tema pela subjetividade da questão.

A metodologia de estudo qualitativa é uma forma menos estruturada usada para obter informações aprofundadas sobre a motivação e o raciocínio das pessoas, com o objetivo final de desenvolver um entendimento profundo sobre o tema estudado. Ela tem como finalidade conseguir dados voltados para compreender as atitudes, motivações e comportamentos de determinado grupo para entendermos o problema do ponto de vista deste grupo em questão.

A escolha da pesquisa qualitativa se deu pela natureza investigativa do trabalho, que tem como objetivo descobrir os efeitos da inclusão de PcDs na cultura organizacional da Reserva.

Segundo Strauss \& Corbin (1998), o método de pesquisa é um conjunto de procedimentos e técnicas utilizados para se coletar e analisar os dados. $O$ método fornece os meios para se alcançar o objetivo proposto, ou seja, são as "ferramentas" das quais fazemos uso na pesquisa, a fim de responder nossa questão.

\subsection{Universo da pesquisa:}

O universo de pesquisa, segundo Stevenson (1981), consiste no todo pesquisado, do qual se extrai uma parcela que será examinada e que recebe $o$ nome de amostra. Ele observa os efeitos da inserção de PcDs na cultura organizacional da Reserva.

A realização da presente pesquisa foi feita de forma que fosse possível observar da melhor forma os efeitos da inclusão dessas pessoas, através da visão de pessoas com deficiência, diretores de $\mathrm{RH}$ e fundadores da Reserva. O programa de inclusão desse grupo na empresa Reserva vem ocorrendo de forma efetiva. A analise dos efeitos dessa inserção sobre a cultura organizacional serão o tema principal na análise apresentada.

\subsection{Coleta de dados:}

A coleta de dados foi feita através da analise da cultura da empresa e de uma revisão bibliográfica, envolvendo livros, teses, dissertações e noticias com o objetivo de embasar tópicos referentes à inclusão de PcDs para a empresa, analisando o problema e os objetivos a serem estudados. 
Com a pesquisa iremos apresentar dados extremamente subjetivos, ou seja, os resultados obtidos não vão ser contabilizados com $100 \%$ de certeza. Para facilitar a interpretação dos dados, vão ser demonstradas situações atuais que irão mostrar as circunstancias para a entrada dessas pessoas, mostrando os efeitos dessa diversidade para a cultura organizacional da empresa Reserva.

\subsection{Tratamento dos dados:}

Foi utilizado a abordagem qualitativa que busca identificar e analisar esses dados que não podem ser mensurados numericamente. Nessa pesquisa, o tratamento dos dados vai analisar como que o processo de inclusão pode gerar mudanças na cultura da empresa, havendo o engajamento por parte da empresa em relação a importância de ter pessoas diferentes que se complementam.

A análise dos dados qualitativos obtidos durante o estudo foi feito através da analise da situação atual da empresa. Por meio desta análise foram identificados os pontos que mereciam uma maior atenção e que deveriam ser mais enfatizados pela empresa para que o processo de inclusão possa ser positivo para ambos.

\subsection{Limitação do estudo:}

O modelo não é capaz de garantir com precisão os efeitos dessa inclusão desse grupo na empresa, devido à subjetividade da questão apresentada e por não ser possível analisar o tempo necessário para que a inclusão possa afetar a cultura organizacional da empresa Reserva. 


\section{Análise da pesquisa:}

\subsection{O cenário atual da Reserva:}

Esta pesquisa teve como cenário a empresa Reserva que está num processo de inclusão de $\mathrm{PcDs}$ dentro da organização, localizada em São Cristovão no Rio de Janeiro. A Reserva valoriza a diversidade dentro da organização, tendo a empresa colaboradores de diferentes gêneros, idades, culturas, classes sociais, orientações sexuais e intelectuais e até padrões estéticos, estando no processo de incluir PcDs dentro da empresa. A Reserva acredita que com visões diferentes por parte de seus funcionários, a empresa conseguira melhorar a visão de seus negócios, pois a pluralidade irá permitir que um mesmo assunto seja tratado com diversas perspectivas criando um ambiente propício para inovação.

A Reserva sabe da importância de criar um ambiente mais adequado para receber essas pessoas, visto que a falta de acessibilidade na empresa é um barato que pode sair caro. A Reserva entende que é preciso ir além da acessibilidade, pois o preconceito e a discriminação estão impregnados na sociedade, com isso a organização sabe da importância de gerar condições de trabalho mais adequadas para que esses funcionários se sintam mais a vontade e consigam interagir bem com o resto da empresa.

A Reserva valoriza o trabalho em equipe por acreditar que essa forma de tarefa gera um ambiente mais benéfico para o sucesso. A empresa trabalha para que seus trabalhadores estejam sempre em conjunto sem pensar nas diferenças como uma barreira para esse trabalho em equipe.

Segundo Rony Meisler fundador da Reserva, "se não sabemos o que é um erro, estamos menos sujeitos a ter medo de cometê-lo. O medo é inimigo da inovação", ou seja, se a empresa tiver medo ou receio de contratar funcionários por conta da sua limitação, ela estaria indo contra a sua política de valorizar a diversidade por puro preconceito.

Os funcionários PCDs podem errar como qualquer um sem haver um tratamento diferenciado por conta de sua limitação. A empresa deve gerar condições para receber bem esse grupo de pessoas, uma vez que estamos em fase de desconstrução e aprendizado sobre as mudanças que vem ocorrendo na sociedade e seus impactos.

A Reserva considera que não basta apenas seguir a Lei de Cotas ํo 8.213/91, por achar que ela não contribui da melhor forma para a inclusão das pessoas com deficiência no mercado de trabalho. A empresa considera que deve haver alterações nessa lei, já que a melhor maneira de incluir essas pessoas seria pensando melhor sobre como fazer isso, revolucionando assim 
esse processo de inserção, onde seja valorizado as qualidades dessas pessoas.

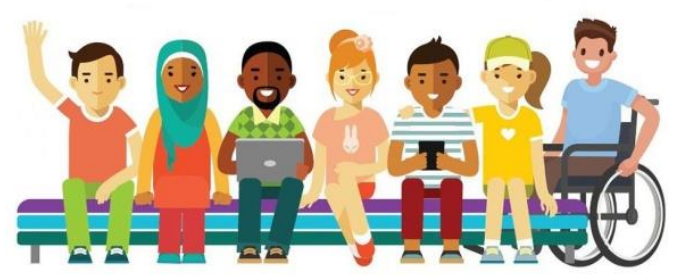

4.2 Processo de inclusão e trabalho em equipe:

A Reserva trabalha com muita flexibilidade, para encontrar os melhores funcionários, sejam eles pessoas com deficiência ou não, pois a empresa sabe que para construir um ambiente no qual seus colaboradores são incentivados a dar o seu melhor, deve haver um processo de diferenciação entre seus funcionários.

As pessoas com deficiência não devem ser tratadas como um "herói", mas também não deve haver nenhum sinal de pena por parte das outras pessoas, pois esse grupo é muito discriminado pela sociedade e o Pcd merece ser tratado como uma pessoa "normal".

O processo de inclusão busca desenvolver valores que são incorporados à cultura da empresa. O resultado é que há uma melhora na imagem da Reserva que terá uma cultura inclusiva que irá proporcionar uma melhora no ambiente de trabalho, sendo importante fazer com que todos os seus funcionários se sintam parte do negócio.

Além disso, o líder deve ir junto e estar sempre presente nessa jornada, visto que ele deve estimular o dialogo entre as equipes, partindo da gestão a conversa, onde a equipe terá um olhar mais positivo para a inclusão dessas pessoas. A Reserva acredita que "o que você é por dentro é o que te coloca aqui dentro", ou seja, a organização sabe que cada um é do seu jeito e que deve haver o respeito de cada um com a diferença.

A Reserva segue a ideia que o "afeto move montanhas", onde a vibração de cada um eleva o animo na hora de trabalhar. O processo de inclusão busca reafirmar isso, onde cada funcionário deve ajudar o outro, buscando o melhor para a empresa através do trabalho em equipe, onde a empresa consiga ter uma cultura que busque a união de seus funcionários para reforçar a ideia de ajudar o outro, reforçando a importância dessa mudança cultural.

A organização busca revolucionar o mercado de moda no Brasil, sempre buscando se conectar com a realidade que cada um vive, sendo mais criativa, 
colaborativa e principalmente humana, respeitando sempre as diferenças entre as pessoas.

A Reserva é uma marca que procura ouvir seus clientes e funcionários, buscando emocionar, cuidar e surpreender as pessoas todos os dias. A empresa acredita que cada um "é livre pra ser o que você quiser", mostrando que o respeito e a tolerância são fundamentais nesse processo de inclusão.

Assim, o processo de inclusão deve sempre estar relacionado com a cultura da empresa, visto que a empresa valoriza a sua cultura, onde ela enfatiza o pensamento de que todos somos iguais e que devemos respeitar a diferença entre as pessoas.

\subsection{Efeitos da inclusão:}

O processo de inclusão de PcDs na Reserva reforça a imagem da mesma perante a sociedade. A empresa está contribuindo para um mundo mais igualitário. Segundo seus dois fundadores: a empresa valoriza a inclusão dessas pessoas, trazendo uma mudança cultural para a empresa, visto que aceitar a diversidade não é apenas lidar com a diferença, mas sim respeitar as ideias, culturas e histórias de vida de cada um, sem desrespeitar as diferenças, pois os portadores de deficiência são pessoas que, muitas vezes, são exemplos de superação e persistência para os demais colaboradores, fortalecendo a importância da inclusão desse grupo.

A inclusão afeta o clima organizacional da empresa, mas não sendo isso algo fácil de acontecer, pois quando incluímos uma pessoa em nosso mundo, nos devemos saber toda a complexidade da situação, visto que devemos nos tornar seres mais empáticos para entendermos a situação do outro, pensando melhor nas dificuldades vividas por esse grupo na sociedade.

O clima organizacional é o reflexo dos efeitos da cultura no todo da empresa, ou seja, ele influencia e é influenciado pelo comportamento de todos os envolvidos com a organização. Essa mudança cultural, necessita de mais tempo para acontecer, sendo a analise do clima organizacional essencial nesse processo, visto que ele representa uma natureza mais transitória, podendo ser administrado tanto a curto quanto a médio prazo, sendo possível analisar as mudanças ocorridas dentro da Reserva.

A falta de acessibilidade inibe a empresa a contratar alguns tipos de PCDs como seu funcionário, sendo isso um problema para a Reserva, visto que um cadeirante não tem condições de subir uma escada para dar inicio ao seu dia de trabalho, o que representa um empecilho em buscar a diversidade com esse grupo de pessoas.

Esse processo deve ser visto com calma pela empresa, as dificuldades estruturais reforçam a ideia de Pastore (2000), onde a informação das pessoas, 
a conscientização da sociedade e os esforços das instituições sociais são decisivos para reforçar a integração dos portadores de deficiência na vida social e profissional.

Os gestores devem selecionar com cuidado as atividades passadas para esse grupo, pois os PcDs têm dificuldades em realizar algumas atividades por conta das suas limitações, porém a Reserva acredita que isso não pode ser um impedimento para o processo de inclusão. O convívio diário com essas pessoas é fundamental para a empresa aprender a lidar com tais limitações, ou seja, todos ganham com a inclusão, visto que desenvolvendo melhor a questão do lado humano de pensar no próximo, que todos somos diferentes, que é preciso lidar bem com todas as pessoas e que a inclusão é uma forma de valorizar tais pessoas, gerando um clima mais agradável dentro da empresa.

Assim, a Reserva acredita que a inclusão pode afetar a cultura da empresa, pois é uma mudança de pensamentos, mesmo com alguns colaboradores ficando inseguros com o novo, com as devidas orientações é possível se adaptar bem à nova realidade e assim cada colaborador perceber que a cultura organizacional é formada por todas as pessoas da organização sendo importante a conscientização do grupo nesse processo.

Portanto, tudo o que foi dito acima vem de acordo com que dizem Sobral e Peci (2008), que a administração da diversidade proporciona 0 desenvolvimento de cada um, de modo não apenas a tolerar ou acolher todos os tipos de diferenças, mas apoiar, nutrir e utilizar essas diferenças para todos da organização.

Assim, segundo a gestora de RH da Reserva, a entrada de PCDs dentro da empresa, possibilita uma maior aprendizagem e acaba sendo um estimulo para os outros funcionários, ou seja, um aprendizado no dia a dia com a convivência com essas pessoas, tendo uma mudança cultural com o grupo.

\subsection{Por que Mudar?}

A Reserva é uma empresa que estimula a diversidade em seu escritório, porém acaba esbarrando na falta de acessibilidade para ter alguns tipos de PCDs como seus funcionários. A empresa sabe que hoje não tem condições de receber pessoas com impedimentos de se locomover, pois para entrar em seu escritório é necessário subir uma escada e alguns degraus dentro de seu local de trabalho.

Assim, a estrutura da empresa acaba sendo a grande barreira para 0 aumento desse processo de inclusão, porém a organização trabalha para promover um grupo que pense e estimule a questão de acessibilidade na sede e que proponha algumas ações que tratem desse problema. 
Os líderes da empresa trabalham para estimular mudanças na organização, gerando condições para o aumento de funcionários PCDs na empresa. A Reserva sabe que a inclusão de PCDs dentro da empresa deve aumentar, visto que a sua cultura estimula a ideia de que cada pessoa tem o seu jeito de ser e que os PCDs são pessoas super agradáveis e capazes de gerar mudanças na forma de pensar da sociedade como um todo.

Assim, isso gera uma necessidade de mudança para a empresa, visto que 0 ambiente organizacional onde a empresa fica não gera condições adequadas para receber tal grupo, mas a Reserva esta em fase de desconstrução e aprendizado sobre as mudanças que vem ocorrendo na sociedade, a inclusão social de PCDs no mercado de trabalho tem o papel de estimular tais mudanças.

Deste modo, a empresa terá condições de receber qualquer tipo de pessoa como seu funcionário, pois assim, a empresa poderá ter uma cultura mais inclusiva, onde possa desenvolver pessoalmente e profissionalmente seus funcionários, reduzindo os conflitos dentro da empresa, havendo políticas bem estabelecidas com uma comunicação bem clara, reduzindo assim a chance de mal entendidos causados pela diversidade, havendo assim um cenário mais saudável dentro da empresa.

A Reserva busca com essa diversidade dentro de seu ambiente de trabalho gerar uma cultura mais inclusiva, onde seus funcionários estimulem a inclusão dessas pessoas e a empresa consiga se adequar para a chegada de funcionários PCDs e assim valorizar a criatividade entre seus funcionários, estimulando a ideia de qualquer funcionário se sinta bem vindo dentro da empresa para trabalhar com segurança e confiança, respeitando a própria cultura da empresa que estimula a diversidade.

\subsection{Etapas de mudança:}

Mudança é o processo de alteração, transformação, troca e modificação. Chiavenato (2006) cita também que "envolve transformação, interrupção, perturbação, ruptura, dependendo da sua intensidade". A partir do estudo interno da organização é possível perceber a importância dessa mudança, visto que as antigas ideias da organização estão no passado, representando uma ideia ruim em relação ao processo de inclusão.

A mudança deve estar sempre junta com a ideia de melhora, havendo a identificação (as pessoas percebem a eficácia da nova atitude ou comportamento e a aceita) e a internalização (as pessoas passam a desempenhar novas atitudes e comportamentos como parte de seu padrão normal de comportamento). 
A Reserva sabe que deve mudar sua estrutura organizacional, visto que a empresa sabe que a falta de acessibilidade pode manchar a imagem da empresa como um todo, tendo que haver mudanças de hábitos dentro da empresa, onde a Reserva sabe das suas necessidades em promover mudanças para valorizar cada pessoa como ser humano.

A Reserva busca ter uma cultura mais inclusiva, onde a empresa busca ter melhores condições de trabalho para seus funcionários, enfatizando a ideia de que as mudanças organizacionais não são necessárias, apenas, para a inclusão de PcDs dentro da empresa, mas sim para valorizar a qualidade de trabalho de seus funcionários, sejam ele PcDs ou não.

O processo de inclusão social deve estimular a ideia de mudança cultural, visto que a mudança de comportamento irá proporcionar um novo pensamento, onde os membros tenham uma cultura mais inclusiva que estimule a chegada de qualquer pessoa como funcionário da Reserva.

\subsection{Cultura organizacional:}

A cultura da empresa esta presente na cabeça de cada funcionário, sendo ela fundamental nesse processo de mudança, visto que a cultura da Reserva já tem a ideia de valorizar a diversidade dentro da empresa. A inclusão de PcDs irá proporcionar mudanças na forma da Reserva ver essas pessoas, visto que a empresa tem consciência de que cada um pode ajudar de alguma forma.

A cultura da Reserva vem da forma de seus representantes perceberem, pensarem e sentirem os problemas de adaptação externa e integração interna da empresa, sendo seus três níveis de cultura os artefatos que mostram a forma como a Reserva inclui novos grupos na empresa, modificando a estrutura e os processos da mesma, mostrando como que a diversidade esta presente no coração da empresa.

Em relação às crenças e valores da Reserva, a empresa demonstra a importância de demonstrar paixão no relacionamento entre seus colaboradores, visto que o processo de socialização esta muito presente na cultura da Reserva, ou seja, qualquer pessoa é muito bem recebida dentro da empresa.

Os pressupostos básicos da Reserva estão relacionados a forma como que a empresa respeita a diferença entre as pessoas, respeitando a natureza humana de cada um, visto que cada pessoa é criador e criatura de sua cultura, ou seja, a empresa acredita que sua cultura vem a partir da ideia de que existe algo que cria significado e possibilidade de existência a partir da cultura de cada membro da empresa. 
Ao analisarmos se a inserção de PCDs dentro da empresa afetou a cultura organizacional da mesma, podemos notar que isso mudou a forma da Reserva enxergar o mundo, havendo uma mudança de pensamentos dentro da empresa, ou seja, mesmo com os eolaboradores da empresa ficando inseguros com a novidade, o dia a dia acaba Estimulando a nova realidade. Isso é uma mudança no cotidiano da empresa, ou seja, além de uma mudança de cultura, acaba sendo uma mudança para todos os envolvidos com a empresa.

A cultura da organização varia de acordo com as necessidades impostas pelo ambiente, demonstrando o interesse da empresa em relação ao que ela acha certo. Ela é vista como o DNA da empresa, sendo formada a partir das relações interpessoais entre funcionários sempre estando de acordo com o posicionamento da empresa.

A mudbança cultural deve começar pelo respeito entre todos os envopelvidos com a organização. Os funcionários devem ter a consciência que os Pcds têm suas limitações, mas são pessoas "normais", tendo que ser cobrados na hora do erro e elogiado na hora do acerto, porém o que não pode faltar nunca é o respeito e a tolerância com essas pessoas.

A Reserva busca seguir esse objetivo na integra, a empresa acredita que toda pessoa pode contribuir de alguma forma para o bem da organização. A empresa tem em sua cultura a ideia de valorizar o individuo. $O$ objetivo de incluir funcionários PcDs dentro da empresa começou a partir da visão de seus fundadores, onde cada pessoa tem seu papel na sociedade, sendo cada um do seu jeito, tendo a cultura da empresa o papel de proporcionar essa inclusão.

A missão da Reserva enfatiza a ideia de "ser um amigo e não uma marca". Seus valores buscam enfatizar a ideia de ser feliz acima de tudo, sempre buscar fazer o bem, ser amigo de todos, ser respeitoso, realizar seus sonhos, ser corajoso, ser autentico, ser você mesmo e respeita as outras pessoas, o que vai de acordo com a ideia de ter uma cultura mais inclusiva.

A paixão esta sempre presente na cabeça e nas ações de cada membro da empresa, mostrando a força de sua cultura. A Reserva sabe que para incluir essas pessoas, não deve haver nenhum tratamento diferenciado por conta de tal limitação, pois todos devem ser tratados da mesma forma.

Assim, com o passar do tempo, os colaboradores vão entendendo que os funcionários PCDs são capazes de fazer as mesmas coisas que os demais, porém havendo o respeito a tais limitações desses funcionários para a empresa chegar nessa nova cultura. 


\section{Conclusão:}

O objetivo do presente trabalho foi analisar os efeitos da inclusão de PCDs para a cultura organizacional da empresa Reserva no Rio de Janeiro com seu escritório localizado em São Cristovão. Com base na analise, feita a Reserva tem algumas dificuldades em incluis mais PCDs dentro da empresa pela falta de acessibilidade em seu escritório, porém a cultura organizacional da empresa está em processo de adaptação para a entrada dessas pessoas.

Conclui-se que a cultura da Reserva está no caminho certo para esse processo de inclusão, visto que seus funcionários $\mathrm{PCDs}$ são valorizados dentro da empresa, porém falta condições da empresa receber mais funcionários PCDs devido a estrutura da empresa.

A empresa está planejando um início de um trabalho para debater a questão de acessibilidade em sua sede para promover ações que tratem desse problema e assim melhorar esse processo de inclusão social dentro da Reserva.

A cultura está presente na cabeça de cada funcionário da Reserva, sendo ela o principal mecanismo de mudança desse processo, onde a a inclusão de pessoas com deficiência no ambiente de trabalho geram mudanças na cultura organizacional da mesma, mas não sendo algo simples de acontecer, pois não basta selecionar um PCD e sua cultura vai mudar automaticamente.

Os efeitos da integração entre funcionários PCDs e outros funcionários se mostram favoráveis para uma mudança cultural da Reserva, pois essa inclusão contribui para a melhora do clima da empresa, visto que a partir da convivência com PCDs as pessoas começam a perceber que nada é impossível e que o pré julgamento acaba sendo uma armadilha para a sociedade como um todo.

A cultura da empresa busca ser adaptativa com essa situação, visto que a cultura deve favorecer as transformações ocorridas na sociedade. O grupo da Reserva é um grupo bem diversificado, sendo mais fácil lidar bem com essa nova diferença no campo de trabalho e devera aceitar bem a adaptação para entrada de PCDs dentro da empresa.

A mudança na estrutura da empresa deve acontecer para a perfeição na execução dessa questão, visto que essa transformação é essencial para valorizar a chegada de PCDs dentro da empresa, pois não será possível observar da melhor forma os efeitos da inclusão sem condições mínimas para receber alguns grupos de deficientes. 
Com melhores condições, a empresa conseguira ter um gerenciamento cultural mais eficaz, onde cada funcionário vai em seu dia a dia de trabalho faça sua parte nesse processo, sendo possível analisar com mais clareza os efeitos dessa inclusão na cultura organizacional da empresa.

As políticas de $\mathrm{RH}$ da Reserva são elementos fundamentais nesse processo, visto que elas têm o papel de estimular o convívio entre seus funcionários para uma possível melhora na cultura da Reserva. 


\section{Referências bibliográficas}

Alves, M., \& Galeão-Silva, L. G. (2004). A crítica da gestão da diversidade nas organizações. RAE - Revista de Administração de Empresas.

AURELIO, Marco. Referencial teórico: cultura organizacional. 2014. Disponível em: <https://www.maxwell.vrac.puc-rio.br/11214/11214_3.PDF>. Acesso em: 1 jan. 2014.

BAHIA; SCHOMMER. A partir da década de 1970, os direitos das pessoas com deficiência tiveram espaço na agenda da política internacional. 2010. Disponível em: <https://diversa.o'prg.br/artigos/o-desenvolvimento-dealunos-com-deficiencia-intelectual-e-o-mito-da-idade-

mental/?gclid=CjOKCQiArqPgBRCRARIsAPwIHoWU-zwMB3xosUYhkPVDBT_1GPTWUOudvLkXXkz61QQg5tni6QRkpoaAmm4EALw_wcB>. Acesso em: 11 jan. 2010.

BURNETT, Edward. Cultura ou civilização. 1996.

CCR. Inclusão profissional traz motivação e desafios para pessoas com deficiência: Cresce ano a ano o número de portadores de necessidades especiais com postos nas empresas.. 2018. Disponível em: <https://g1.globo.com/especial-publicitario/em-

movimento/ccr/noticia/inclusao-profissional-traz-motivacao-e-desafios-parapessoas-com-deficiencia.ghtml>. Acesso em: 31 jan. 2018.

D'AMARAL, Tereza Costa. Preconceito é entrave para a contratação de pessoas com deficiência. 2018. Disponível em: <http://agenciabrasil.ebc.com.br/direitos-humanos/noticia/2018-

09/preconceito-e-entrave-para-contratacao-de-pessoas-com-deficiencias. Acesso em: 21 set. 2018.

https://g1.globo.com/especial-publicitario/em-

movimento/ccr/noticia/inclusao-profissional-traz-motivacao-e-desafios-parapessoas-com-deficiencia.ghtml

HABER, Jaques. A Inclusão De Profissionais Com Deficiência No Mercado De Trabalho: Um Panorama Positivo para uma Mudança Necessária. 2012. Disponível em: <http://blog.isocial.com.br/a-inclusao-de-profissionais-comdeficiencia-no-mercado-de-trabalho-um-panorama-positivo-para-uma-

mudanca-necessaria/>. Acesso em: 20 ago. 2012.

HOFSTEDE. Cultura organizacional. 1997. Disponível em: <Pearson Education - Br>. Acesso em: 1 jan. 1997.

IBDD. Uma pesquisa feita pelo IBDD e pelo DataSenado mostra que $77 \%$ das pessoas com deficiência acreditam que os direitos não são respeitados no país. A pesquisa, feita em 2010, é considerada a mais completa por ter entrevistado diretamente as pessoas com deficiência. Segundo Teresa, ela ainda reflete o cenário atual. 2010. Disponível em: $<$ http://agenciabrasil.ebc.com.br/direitos-humanos/noticia/2018- 
09/preconceito-e-entrave-para-contratacao-de-pessoas-com-deficiencia>. Acesso em: 11 jan. 2010.

JULIO, Rennan A.. As 22 empresas mais humanizadas do Brasil: Estudo foi divulgado durante o CCLAC 2019, evento de capitalismo consciente realizado em São Paulo. 2019. Epoca. Disponível em: $<$ https://epocanegocios.globo.com/Empresa/noticia/2019/03/22-empresasmais-humanizadas-do-brasil.html>.

KENNEDY, Deal \&. Cultura organizacional. 2008. Disponível em: <Pearson Education - Br>. Acesso em: 1 jan. 2008.

MACIEL, Maria Regina Cazzaniga. PORTADORES DE DEFICIÊNCIA: a questão da inclusão social. 2000. Disponível em: <http://www.scielo.br/scielo.php?script=sci_arttext\&pid=S010288392000000200008>. Acesso em: 1 abr. 2000.

NUNES, Luma Morena de Souza. Os desafios do processo de inclusão de pessoas com deficiência no ambiente corporativo: estudo de caso de uma multinacional francesa. 2014. Disponível em: <file:///C:/Users/Filipe/Downloads/Monografia_Luma\%20Morena\%20de\%20 Souza\%20Nunes\%20(1).pdf>. Acesso em: 1 jun. 2014.

RIBEIRO; CARNEIRO. Em 1983, tivemos a Organização Internacional do Trabalho (OIT) falando da necessidade da adoção de medidas que fossem capazes de incrementar e favorecer o acesso dos portadores de deficiência a ter uma profissão. 2009. Disponível em: $<$ http://www.scielo.br/scielo.php?script=sci_arttext\&pid=S0102$88392000000200008>$. Acesso em: 11 jan. 2009.

Scielo.br/scielo.php?script=sci_arttext\&pid=S0102-88392000000200008 SOBRAL, Filipe; PECl, Alketta. Administração: Teoria e Prática No Contexto Brasileiro. 2015. Disponível em: <Pearson Education - Br>. Acesso em: 1 jan. 2015.

TYLOR, Edward Burnett. A ciência da cultura. In: CASTRO, Cellos. Evolucionismo cultural: textos de Morgan, Tylor e Frazer. Textos selecionados, apresentação e revisão, Celso Castro. Rio de Janeiro: Jorge Zahar Ed, 2005. pp. 67-99.

TYLOR, Edward Burnett. [1865]. Researches into the Early History of Mankind and the Development of Civilization. Second edition. London: John Murray, Albemarle Street. 1870.

TOKARNIA, Mariana. Preconceito é entrave para a contratação de pessoas com deficiência. 2018.2 Disponível em: <http://agenciabrasil.ebc.com.br/direitos-humanos/noticia/201809/preconceito-e-entrave-para-contratacao-de-pessoas-com-deficiencia>. Acesso em: 21 set. 2018. 